\title{
O Papel do microcrédito no ambiente local: Evidências a partir do programa Banco da Família em Santa Catarina
}

The rules of microcredit in the local sphere:

Evidences from Family Bank Program in the Santa Catarina State

\author{
Lauro Francisco Mattei \\ 1.mattei@ufsc.br \\ Universidade Federal de Santa Catarina \\ Roniel Antonio da Silva \\ ereroni@yahoo.com.br \\ Banco do Brasil
}

Resumo: Neste artigo são analisados possíveis impactos do microcrédito no ambiente local a partir de um estudo de caso junto ao Banco da Família, localizado na cidade de Lages, estado de Santa Catarina. Inicialmente faz-se um breve debate sobre o surgimento e a expansão do microcrédito no Brasil e no estado de Santa Catarina. Posteriormente descrevem-se as principais instituições de microcrédito que atuam no estado catarinense. A partir de então é apresentado o estudo de caso realizado junto ao Banco da Família, com aplicação de entrevistas com os clientes do referido banco e também com os agentes de crédito. Dentre os principais resultados da pesquisa de campo destacaram-se as melhorias e expansão dos negócios, bem como as contribuições do microcrédito para a melhoria da qualidade de vida. Além disso, ficaram evidenciadas também as inter-relações entre os programas de microcrédito e o desenvolvimento local.

Palavras-chave: Microcrédito; Desenvolvimento local; Banco da família

\begin{abstract}
In this article we are analyzing the effects of microfinance program in the local situation with emphases on the Family Bank experience in the city called Lages. In the beginning, we wrote a short discussion about this credit system in Brazil and Santa Catarina State. After them, we described the most important institutions that are working in this area in Santa Catarina State. Finally, we presented a case of study that took a place in Lages with customers and workers of Family Bank Agency. The main results of this study were a better quality of life and an expansion of the business, with positive effects also in the local development conditions.
\end{abstract}

Keywords: Microfinance; Local development; Family bank agency

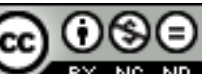

\section{Introdução}

O microcrédito passou a fazer parte de iniciativas recentes de políticas públicas que procuram resolver problemas econômicos e sociais de distintas parcelas da população, geralmente sem acesso ao sistema bancário de crédito tradicional ou ao sistema de crédito de lojas de departamentos e de grandes redes de magazines comerciais. 
A partir das últimas décadas do século $\mathrm{XX}$, muitos governos nacionais, em aliança com organismos internacionais, como são os casos do Banco Mundial (BM) e da Organização das Nações Unidas (ONU), criaram diversos programas para erradicação da pobreza e políticas públicas para indução do desenvolvimento, visando atender as metas do milênio ${ }^{1}$. Neste contexto, foram criados programas de incentivo às atividades produtivas, via expansão do crédito bancário, objetivando melhorar a qualidade de vida da população que se encontrava em condições de pobreza e sem acesso ao sistema financeiro.

É neste período que o microcrédito ganhou maior visibilidade, especialmente a partir dos resultados positivos apresentados pela experiência do Grameen Bank ${ }^{2}$, a qual provocou expressivas mudanças econômicas, sociais e culturais em Bangladesh, tornando-se uma referência mundial nesta área. Isto porque essa experiência provou que é possível mudar o paradigma creditício, seja emprestando recursos para pessoas pobres visando melhorar suas condições de vida, seja mantendo a sustentabilidade financeira das instituições vinculadas a este tipo de crédito.

No Brasil, mesmo que tenham sido desenvolvidas algumas experiências desde os anos de 1970, somente após a segunda metade dos anos de 1990 é que este sistema encontrou melhores condições para ser implementado. Em parte, isso ocorreu devido à estabilização econômica e aos diversos programas destinados à erradicação da pobreza, bem como às políticas públicas voltadas à promoção do desenvolvimento local e regional.

O microcrédito pertence ao ramo das microfinanças e o termo, segundo Soares e Melo (2008 apud Santos e Gois, 2011, p. 24), "refere-se à prestação de serviços financeiros adequados e sustentáveis para a população de baixa renda, historicamente excluída do sistema financeiro tradicional, com utilização de produtos e gestão diferenciados.”.

Ainda de acordo com esses autores, a atividade de microcrédito é aquela que, no contexto das microfinanças, se dedica a prestar esses serviços exclusivamente a pessoas físicas e jurídicas empreendedoras de pequeno porte, diferenciando-se dos demais tipos de atividade microfinanceira também pela metodologia utilizada, distinta daquela adotada pelas operações de crédito tradicionais. É entendida como principal atividade do setor de

\footnotetext{
${ }^{1} \mathrm{Na}$ Assembleia Geral da ONU realizada em 08.09.2000, com a presença de 191 estados membros, foram estabelecidos os Objetivos de Desenvolvimento do Milênio (ODM). Para tanto, foram definidos 8 objetivos gerais com 22 metas específicas, sendo que o objetivo número 1 era erradicar a pobreza extrema e a fome até 2015.

${ }^{2}$ O Grameen Bank é uma instituição privada organizada sob a forma de sociedade por ações, sendo que o governo de Bangladesh participa com apenas $10 \%$ do total.

Rev. Text. Econ., Florianópolis, v. 21 n. 1, p. 125 - 145, dez/mar. 2018 ISSN 2175-8085
} 
microfinanças pela importância para as políticas públicas de superação da pobreza e também pela geração de trabalho e renda. (Soares e Melo, 2008 apud Santos e Gois, 2011)

No processo de desenvolvimento econômico sabe-se que o crédito é uma ferramenta fundamental. Todavia, o crédito tradicional fornecido pelos bancos necessita geralmente de garantias, histórico dos demandantes, além do atendimento de diversas exigências estipuladas pelos agentes financeiros. É neste contexto que o microcrédito pode fazer a diferença junto à parcela da população que, impossibilitada de tomar crédito junto aos agentes financeiros tradicionais, fica refém de agiotas e de intermediários.

Assim, pensando o desenvolvimento local a partir da premissa de que os atores locais podem se transformar em protagonistas do desenvolvimento, analisa-se a contribuição do microcrédito como ferramenta de impulsão para aquilo que Buarque (2008, p. 25) denomina de "um processo endógeno de mudança que leva ao dinamismo econômico e a melhoria da qualidade de vida da população em pequenas unidades territoriais e agrupamentos humanos".

Este trabalho analisa possíveis impactos do microcrédito no ambiente local, a partir de uma experiência concreta. Para tanto, além desta breve introdução, o artigo contém mais cinco seções. A primeira delas discute a inter-relação entre os programas de microcrédito e seus efeitos no curso do desenvolvimento local. A segunda seção faz uma breve resenha sobre o surgimento e expansão do microcrédito no Brasil e no estado de Santa Catarina, procurando mostrar o cenário atual. A terceira seção apresenta o histórico e a trajetória do programa Banco da Família na cidade de Lages (SC), realçando algumas informações gerais. Na quarta seção são discutidos os principais resultados do estudo de caso, a partir das informações oriundas de entrevistas aplicadas junto aos clientes e agentes de crédito do Banco da Família. Finalmente, a quinta seção apresenta as considerações finais do trabalho, destacando alguns aspectos relevantes do programa, mas também chamando atenção para a necessidade de estudos mais abrangentes sobre a temática tratada neste trabalho.

\section{1 - MICROCRÉDITO E DESENVOLVIMENTO LOCAL}

A palavra crédito significa confiança, pois deriva das palavras latinas credere e creditum. Para Schumpeter (1982), quem precisa desta confiança para que haja desenvolvimento econômico é o empresário, pois é para este que o crédito é essencial no processo de desenvolvimento econômico. É importante destacar que o empresário, para esse 
autor, não é simplesmente um administrador, mas sim um empreendedor com capacidade de fazer inovações contínuas.

Esse autor descarta todas as outras formas de crédito que não sejam essenciais, tais como o crédito para consumo, para repor estoques, para manter fluxos diários e para a manutenção de negócios existentes que podem sofrer contratempos. Neste sentido, o papel do crédito para o desenvolvimento econômico, segundo Schumpeter (1982), é criar poder de compra ao empresário para estimular as inovações as quais, por sua vez, venham a induzir novas combinações de meios de produção que resultem em novos produtos nos mercados.

Para tanto, o cerne do fenômeno do crédito é

\begin{abstract}
"essencialmente a criação do poder de compra com o propósito de transferi-lo ao empresário, mas não simplesmente a transferência de poder de compra existente. A criação de poder de compra caracteriza, em princípio, o método pelo qual o desenvolvimento é levado a cabo num sistema com propriedade privada e divisão do trabalho. Através do crédito, os empresários obtêm acesso à corrente social dos bens antes que tenham adquirido o direito normal a ela. Ele substitui temporariamente, por assim dizer, o próprio direito por uma ficção deste. A concessão de crédito opera nesse sentido como uma ordem para o sistema econômico se acomodar aos propósitos do empresário, como um comando sobre os bens de que necessita: significa confiar-lhe forças produtivas. É só assim que o desenvolvimento econômico poderia surgir a partir do mero fluxo circular em equilíbrio perfeito. E essa função constitui a pedra angular para a moderna estrutura de crédito" (Schumpeter, 1982 p.74).
\end{abstract}

A partir desses elementos fica clara a condição e importância do crédito no desenvolvimento econômico. De acordo com Stiglitz e Weiss (1981, apud Chaves, Martins e Zica 2007, p.2) “o acesso ao crédito é uma das mais importantes ferramentas ao desenvolvimento econômico de um país." Esses autores mencionam, ainda, que o acesso à obtenção de recursos para aumentar a capacidade produtiva através de investimentos, aumenta o faturamento e gera mais empregos contribuindo para a permanência e sobrevivência das empresas no mercado.

Apesar dessa importância, sabe-se que o acesso ao crédito possui fatores limitadores, com destaque para os altos custos financeiros e para as restrições que geralmente são impostas pelos agentes financeiros. Além disso, sabe-se também que a demanda por crédito ainda não atendida é alta, especialmente para segmentos de produtores que operam em atividades de pequeno porte e/ou na informalidade. Exatamente para enfrentar esses desafios, mais recentemente passou-se a ter a opção do microcrédito.

Embora existam registros de experiências desde o século XV na Inglaterra, com instituições de caridade; no século XIX na Alemanha, com as cooperativas de crédito; e no século XX nos EUA, com os fundos de ajuda (Hollis e Sweetmann 1998, apud Lima, 2009), é a experiência de Muhammad Yunus, em Bangladesh, uma das principais referências neste Rev. Text. Econ., Florianópolis, v. 21 n. 1, p. 125 -145, dez/mar. 2018 ISSN 2175-8085 
debate. Isto porque este professor de economia abalou o pensamento econômico quando largou as salas de aula no ano de 1976 e se tornou o "banqueiro dos pobres" naquele país, repetindo assim a prática de Jonathan Swift ${ }^{3}$.

Yunus recebeu esta denominação pelo fato de emprestar pequenas quantias a muitas pessoas que faziam parte da população que era excluída do sistema de crédito bancário. Os empréstimos são dirigidos aos empreendedores para investimentos em ferramentas e matériasprimas para fomentar a produção, não sendo créditos para financiar o consumo. Assim, o Gramem Bank, segundo Yunus (2000, p. 155) “preocupa-se não apenas com mudanças econômicas, mas também mudanças sociais, pois queremos que as mulheres, de cidadãs de segunda categoria, tornem-se pessoas responsáveis, capazes de resolver suas vidas e a de seus filhos".

De um modo geral, observa-se que a filosofia dessa instituição é destinar crédito exclusivamente para as atividades que sejam capazes de gerar emprego e renda para as pessoas e/ou famílias que se encontram em condições de vida desfavorável, visando eliminar a exploração de particulares que emprestam dinheiro a custos extorsivos, bem como contribuir para a organização dessas parcelas desfavorecidas da população. Com isso, além de fortalecer econômica e socialmente esse público, busca-se eliminar o circuito vicioso da pobreza e da exclusão social.

Para o idealizador do sistema de Bangladesh "o microcrédito pode não ser a solução, mas é uma força de mudanças não só econômica e pessoal, mas também social e política... pois graças ao microcrédito os pobres podem conjugar seu capital humano e seu capital monetário para melhorar as condições de vida e o mundo que os cerca" (Yunus, 2000, p.191192).

Para Mick (2003), atender prioritariamente mulheres significou uma mudança social, além de econômica, pois oportunizou a emancipação da mulher num país onde a religião islâmica é majoritária e mantém certas restrições à participação das pessoas do sexo feminino. Também é considerada uma inovação pelo fato de se contrapor ao sistema creditício tradicional, ao ofertar recursos aos segmentos menos favorecidos da população de forma desburocratizada e com taxas de juros abaixo do mercado, o que comprovadamente contribuiu para retirar muitas pessoas da situação de pobreza e miséria.

\footnotetext{
3 - No início do século XVIII, Jonathan Swift estabeleceu um fundo inicial de 500 libras e passou a emprestar pequenos valores para as pessoas sem acesso a qualquer sistema de crédito, as quais retornavam esses pagamentos semanalmente sem qualquer cobrança de juros, sendo exigido apenas o aval de dois vizinhos como forma de evitar o não pagamento.

Rev. Text. Econ., Florianópolis, v. 21 n. 1, p. 125 -145, dez/mar. 2018 ISSN 2175-8085
} 
Segundo Costa (2010), a revolução financeira de Yunus foi dar crédito ao trabalho, quando sempre se dava ao capital. Costa refere-se à questão do sistema financeiro não estar cumprindo seu papel fundamental na reprodução do capital que seria, segundo esse autor, o de investir através do crédito e assim empregar mais a população economicamente ativa. Neste sentido, para esse autor, o microcrédito passa a ser um importante instrumento de política pública de geração de trabalho e renda para parcelas da população excluída econômica e socialmente.

Esse mesmo autor afirma que ocorre, simultaneamente, uma revolução cultural a partir dos desencadeamentos gerados posteriormente à liberação do microcrédito:

Os trabalhadores adquirem meios de produção. As mulheres, devedoras prioritárias,
tornam-se as maiores responsáveis pelas finanças domésticas. Elas se emancipam. A
revolução do microcrédito é também revolução feminista contra o patriarcalismo.
Logo adiante, prosseguindo o negócio, elas necessitam de informações. Buscam
educação. Torna-se, então, revolução cultural. (COSTA, 2010, p.4).

Para Buarque (2008), em regiões e municípios pobres deve-se reduzir a dependência histórica de transferências de rendas externas compensatórias geradas em outros espaços, perseguindo com rigor o aumento da renda e riqueza local com eficiência, através de atividades econômicas viáveis que promovam a capacidade de concorrer em diferentes níveis de mercado, gerando assim riqueza local e, com isso, desenvolvimento.

Segundo Martins, Vaz e Lima Caldas (2010), o tema do desenvolvimento local não é apenas controverso em termos conceituais, mas também metodológico. Esses autores, citando Benko e Lipietz (1994), afirmam que o desenvolvimento local representa a expansão espacial de um novo arranjo produtivo geral. Por outro lado, mencionam que experiências de desenvolvimento local também têm dinâmicas próprias, não sendo apenas reflexos da reorganização produtiva mais geral. Neste caso, desenvolvem-se um conjunto de instituições, normas e regras destinadas a propagar aspectos da vida local. Essas instituições não incluem apenas os mercados, as escolas e as igrejas, mas também as autoridades, as organizações políticas e as organizações sociais locais.

Normalmente, a noção de desenvolvimento local remete à tomada de decisões "de baixo para cima", em que a capacidade de decidir não é algo exclusivo de órgãos estatais e/ou de entidades empresariais e instituições que eliminem qualquer possibilidade de envolvimento e participação da sociedade local e de suas diferentes formas de organização. Tal inversão na lógica organizativa da sociedade possibilita o exercício da cidadania, amplia o espaço de interação entre os cidadãos, além de dar maior autonomia na definição e gestão dos negócios. 
Neste caso, as potencialidades e os efeitos de novas experiências, como é o caso do microcrédito, são fortemente potencializados.

Isto mostra que o microcrédito e o desenvolvimento local estão intimamente ligados. Mesmo que o microcrédito não seja o único instrumento de promoção do desenvolvimento local, ele pode ser considerado como uma ferramenta importante para ajudar a alavancar as potencialidades locais desde que esteja articulado a um conjunto de políticas que contemplem um plano de desenvolvimento econômico sustentável para a região e até mesmo para o país.

$\mathrm{Na}$ perspectiva do desenvolvimento local, Toscano (2002) afirma que o microcrédito deve ter como finalidade fomentar a construção de cadeias produtivas voltadas à produção de bens, visando atender parcela significativa da demanda local. Todavia, esse autor ressalta que o microcrédito sozinho não é suficiente para desencadear um processo de grandes mudanças locais, necessitando de ações e políticas complementares. Por isso, o autor entende que as distintas potencialidades do microcrédito se manifestam mais fortemente em comunidades com laços fortes de sociabilidade, como associações de moradores, mutirões comunitários, reciclagem de materiais, moedas locais, bancos solidários, etc.

\section{2 - O MICROCRÉDITO NO BRASIL E EM SANTA CATARINA}

A literatura sobre experiências com microcrédito no Brasil, além de ser bastante vasta (Barone, 2002; Mick, 2003; Vasconcelos, 2006; Lima, 2009; Schreiber, 2009; Cacciamali et al, 2014; Santiago, 2014; Nogueira da Costa, 2014), procura mostrar a trajetória e a importância dessa atividade financeira no curso atual do desenvolvimento do país.

Do ponto de vista da evolução do microcrédito no Brasil, pode-se classificar esse processo em três fases distintas ${ }^{4}$. A primeira pode ser entendida a partir da criação do programa UNO - União Nordestina de Assistência a Pequenas Organizações, em 1973 na cidade de Recife. Era uma ONG que estimulava o associativismo combinando crédito e capacitação com atuação em vários estados da região Nordeste. Registre-se que esta experiência desapareceu exatamente dezoito anos após sua fundação, uma vez que dependia de recursos governamentais para sobreviver, num contexto em que não havia outros canais de sustentação financeira deste tipo de organização social como existe atualmente.

$\mathrm{Na}$ mesma época deve-se registrar a criação de ONGs em todo o país, merecendo destaque a ONG Ana Terra, criada no ano de 1987 na cidade de Porto Alegre (RS). Esta foi a

\footnotetext{
${ }^{4}$ Essa classificação é bastante consensual entre praticamente todos os autores mencionados no primeiro parágrafo desta seção.

Rev. Text. Econ., Florianópolis, v. 21 n. 1, p. 125 - 145, dez/mar. 2018 ISSN 2175-8085
} 
primeira unidade da Rede Nacional de Centros de Apoio aos Pequenos Empreendimentos (Rede Ceape), tendo participação da Acción, do Banco Interamericano de Desenvolvimento e da Inter-American Foundation. A Rede CEAPE desenvolveu um conjunto de metodologias de capacitação e de concessão de microcrédito, transformando-se em uma marca da expansão desse sistema no país naquele período.

Além dessas experiências, segundo Santiago (2014), mais duas ações foram importantes neste período. Por um lado, a implantação pelo SINE-Ceará do Programa de Apoio à Microunidades de Produção (PAMICRO), que contou com apoio financeiro do Serviço Alemão de Cooperação Técnica e Social (DED) e do Programa Prioridades Sociais do Governo Sarney. Por outro lado, a criação de uma rede vinculada à Women's World Bank, que mais tarde se consolidaria como o Banco da $\mathrm{Mulher}^{5}$, que implementou um programa de microcrédito com base na metodologia dos grupos solidários de crédito.

A segunda fase diz respeito à década de 1990, podendo ser mais bem compreendida a partir da estabilidade financeira do país, período marcado pela retomada do interesse sobre o tema do crédito popular em várias regiões do país, mesmo que não conformando ainda uma política nacional para o sistema. Nesta fase, Mick (2003) destaca como relevantes os casos da Portosol (1995); VivaCred (1996), CrediAmigo do BNB (1998).

Dentre as principais características desta fase, destacam-se: a operação das atividades com parte dos recursos advindos de bancos governamentais (BNDES, BNB, BB, etc.); o estabelecimento de parcerias com órgãos governamentais (prefeituras municipais, governos estaduais, SEBRAE, etc.) e com organismos internacionais; o estabelecimento de sistemas de empréstimos com prazos definidos e com cobranças de taxas de juros; a intensificação da adoção do sistema do "aval solidário"; e o início mais efetiva da participação do poder público nesta esfera, naquilo que ficou conhecido como os "bancos do povo".

A terceira fase, iniciada no final dos anos de 1990 até os dias atuais, é marcada pela reconfiguração do sistema no país e pela constituição efetiva de um setor nacional com políticas e regras institucionais específicas. Neste caso, o primeiro aspecto a ser ressaltado são as mudanças de natureza legal que foram implementadas a partir de então. A Lei 9.790, de 23 de março de 1999, criou as Organizações da Sociedade Civil de Interesse Público (OSCIP), entidades que podem operar com atividades de microcrédito e outra gama de ações sociais.

Outro aspecto relevante de mudanças na ordem institucional foi a Resolução 2.874, de 26 de julho de 2001, do Conselho Monetário Nacional (CMN), que instituiu as Sociedades de

\footnotetext{
${ }^{5}$ Uma dessas experiências será analisada em uma seção específica deste trabalho. Rev. Text. Econ., Florianópolis, v. 21 n. 1, p. 125 -145, dez/mar. 2018 ISSN 2175-8085
} 
Crédito aos Microempreendedor (SCM) com a finalidade de emprestar crédito aos clientes até o valor limite de R\$ 10 mil. As SCM não podem captar recursos do público, devendo operar com recursos originários de órgãos e instituições nacionais e internacionais de desenvolvimento, orçamentos estaduais e municipais, fundos constitucionais e doações e outras fontes, desde que devidamente registradas no Banco Central do Brasil (BCB).

Do ponto de vista bancário, merece destaque a Lei n. 11.110, de 25 de abril de 2005, que criou o Programa Nacional de Microcrédito Produtivo e Orientado (PNNMPO) no âmbito dos agentes financeiros públicos federais. Neste caso, sobressai o Programa de Microcrédito do BNDES que atua como uma instituição de segundo piso repassando recursos financeiros para entidades da sociedade civil, ONGs e OSCIPs. No âmbito da Caixa Econômica Federal (CEF) criou-se o Programa Crescer, com as mesmas características do programa anterior. Em ambos os casos, o limite dos empréstimos até recentemente era de $\mathrm{R} \$ 15.000,00$.

Com isso,

"o microcrédito provou também que é uma atividade financeira que dá retorno, tem baixa inadimplência, é viável, desde que tenha sua metodologia adaptada às condições locais. Um exemplo ilustra como sua forma de pagamento é muito simples. O cliente em vista possui negócio funcionando pelo há um ano. Pode ser bazar, lanchonete, mercadinho, bar, birosca, etc. Ele pode ser cabelereiro, eletricista, costureira, camelô ou qualquer outro tipo de trabalhador informal. Se ele necessita de dinheiro para comprar mercadorias, máquinas e equipamentos, reformar ou ampliar seu estabelecimento, ele pode escolher quando e quanto pagar pelo pequeno empréstimo" (Nogueira da Costa, 2014:96).

Em Santa Catarina a trajetória do microcrédito é muito parecida com aquela verificada no país, sendo que seu desenvolvimento ocorreu no período recente, sobretudo após a nova ordem jurídica implementada na década de 1990. Do ponto de vista governamental, registrese a experiência derivada do Banco de Desenvolvimento do Estado de Santa Catarina (BADESC), instituição financeira pública que foi instituída pela Lei $\mathrm{n}^{\circ}$. 4.950, de 11 de novembro de 1973, sob a forma de sociedade de economia mista, porém com o objetivo de promover o desenvolvimento econômico e social por meio da concessão de crédito às empresas catarinenses.

Após atuar por mais de 20 anos nesta direção, a partir da segunda metade dos anos de 1990 o BADESC passou a ser uma agência de desenvolvimento com ênfase na linha de microcrédito, cujo primeiro programa foi denominado de "Crédito de Confiança". Esta linha de crédito, na verdade, deu suporte financeiro para que fossem alavancadas diversas iniciativas por todo o estado de Santa Catarina.

Assim, paralelamente a esta ação governamental, também devem ser destacadas outras experiências, como são os casos da Blusol, na cidade de Blumenau; do Banco do 
Empreendedor, em Florianópolis; e do próprio Banco da Família, na cidade de Lages, que será objeto específico de análise neste estudo. O ponto comum em todas essas experiências é o marco jurídico assentado na regulamentação legal de Organização da Sociedade Civil de Interesse Público, sem fins lucrativos.

\section{3 - HISTÓRICO E TRAJETÓRIA DO BANCO DA FAMÍLIA}

O Banco da Família é uma Organização da Sociedade Civil de Interesse Público OSCIP, que iniciou suas operações em 1998 no município de Lages (SC). Inicialmente sua razão social era Banco da Mulher, através de uma iniciativa da Câmara da Mulher Empresária, que arrecadou valores da comunidade empresarial, Associação Comercial e Industrial de Lages e da Prefeitura Municipal.

Em 2001 seu capital era de R\$1.96 milhão, constituído com aportes do BADESC no valor de R\$1.26 milhão; do BNDES no valor de R\$ 500 mil; da Prefeitura de Lages no valor de R \$80 mil; e da iniciativa privada no valor de R 120 mil. Esse capital propiciou na época a concretização de 1.390 operações, envolvendo recursos da ordem de R $\$ 2.57$ milhões ${ }^{6}$.

Em 2003 mudou sua razão social para Banco da Família. Acompanhando a expansão da demanda, foram abertas filiais nos municípios de Curitibanos, São Joaquim, Correia Pinto e Otacílio Costa. Posteriormente, começou a operar também em cidades fora do estado de Santa Catarina, como Caxias do Sul e Vacaria, no Rio Grande do Sul. Desde 2003 a entidade se encontra filiada à Womens World Banking - $\mathrm{WWB}^{7}$

O atual Conselho de Administração é composto por representantes da prefeitura de Lages e representantes da Associação Comercial e Industrial de Lages, BADESC, Associação das Micro e Pequenas Empresas de Lages, Federação das Associações das Micro e Pequenas Empresas de SC e SEBRAE/SC.

Visando inovar e contribuir para eficiência da instituição, em 2010 foi criado o Conselho do Cliente, sendo que a partir desse conselho podem ser sugeridas melhorias e mudanças no funcionamento da instituição. Além disso, ainda existe um programa de

\footnotetext{
${ }^{6}$ - Essas e todas as demais informações constantes desta seção foram obtidas diretamente com a gerência da instituição, sem a existência de uma documentação formal.

${ }^{7}$ Womens World Banking - WWB é uma organização sem fins lucrativos que oferece apoio estratégico, assistência técnica e informações para uma rede mundial de instituições de microfinanças e bancos que oferecem crédito e outros serviços financeiros para empreendedores de baixa renda tendo como foco em sua missão as mulheres mais pobres. Site: http://www.swwb.org/about/about-wwb.

Rev. Text. Econ., Florianópolis, v. 21 n. 1, p. 125 -145, dez/mar. 2018 ISSN 2175-8085
} 
relacionamento que propõe facilidades e descontos para os clientes. $\mathrm{Na}$ área de gestão de pessoas, a entidade possui um programa de desenvolvimento e retenção de colaboradores.

Sua missão é atuar na área de microfinanças com eficiência e atendimento personalizado, contribuindo para a geração de trabalho e melhoria da qualidade de vida das pessoas onde atua. A projeção para o futuro é ser líder dentre as instituições de microfinanças da região, por meio de ações com processos padronizados, valorização dos colaboradores, apoio ao empreendedorismo e ao trabalho da mulher, etc.

O Banco da família possui 62 colaboradores, estando presente em 33 municípios da região do Planalto Serrano: Anita Garibaldi, Bocaina do Sul, Bom Jardim da Serra, Bom Retiro, Brunópolis, Caçador, Calmon, Campo Belo do Sul, Campos Novos, Capão Alto, Caxias do Sul, Cerro Negro, Correia Pinto, Curitibanos, Fraiburgo, Frei Rogério, Joaçaba, Lages, Leblon Régis, Otacílio Costa, Painel, Palmeira, Ponte Alta, Ponte Alta do Norte, Rio das Antas, Rio Rufino, São Joaquim, São Cristóvão do Sul, São José do Cerrito, Santa Cecília, Urubici, Urupema, Vacaria e Videira. Além da Matriz na cidade de Lages, possui mais sete filiais: Caxias do Sul, Vacaria, Caçador, Correia Pinto, Curitibanos, Otacílio Costa e São Joaquim.

Em 2011 chegou a ter uma carteira ativa de $\mathrm{R} \$ 18.055 .805,00$, com 21.956 empréstimos. Quanto ao número de clientes ativos, o Banco da Família possuía 9.310 nos 33 municípios de abrangência em Santa Catarina e no Rio Grande do Sul.

Quanto às linhas de crédito, nota-se que o Banco da Família possuía cinco linhas de crédito: Microcrédito, Reforma e Construção, Troca de Cheques, Grupo Solidário, e BF Casa.

O Microcrédito destina-se aos investimentos em capital de giro, investimento fixo e recursos para reformas de estabelecimentos. A taxa de juros cobrada era de 3,29\% ao mês com prazo de vencimento de até 18 meses. Quem pode solicitar o crédito são clientes que residem, ao menos, um ano no município; que não possuam SPC nem SERASA; que possuam a atividade no mínimo há seis meses; e com idade entre 18 anos e 65 anos.

A linha de troca de cheques tem uma taxa mais atrativa e menos burocracia, não sendo necessário avalista pelo fato de o próprio cheque ser a garantia. Os cheques aceitos são aqueles com mais de seis meses de abertura da conta e sem restrições. A taxa é de 2,99\% ao mês e o prazo máximo é de 180 dias, pois este é o prazo de prescrição do cheque recebido na mesma praça. Já a linha de reforma e construção se diferencia no objetivo e na taxa de juros, tendo um custo variável a partir de $3,55 \%$ ao mês. 
Uma inovação introduzida na prática do programa Banco da Família é o Grupo Solidário, sendo necessário que 3 a 6 pessoas se unam para solicitar empréstimos, onde cada membro terá direito ao primeiro empréstimo no valor máximo de $\mathrm{R} \$ 2.000,00$ por pessoa num prazo de até 10 parcelas mensais. Esta metodologia se parece com a experiência do Gramem Bank, pois cada membro garante o pagamento do empréstimo dos demais.

Outra inovação ocorreu na linha Banco Família Casa. Em parceria com a empresa Reflormar foi desenvolvida uma linha de crédito para financiar casas populares de madeira. $\mathrm{O}$ Banco da Família é o responsável pela operação e orientação financeira, na qual os clientes podem adquirir três modalidades de casas que acompanham um kit de madeiramento completo com portas, janelas e cobertura. $\mathrm{O}$ banheiro pode ser financiado com a concessão de um valor excedente em até $20 \%$ do valor do kit casa.

Segundo a Revista Força do Microcrédito Catarinense (2012), o Banco da Família contribuiu, nos últimos 14 anos, para a manutenção de aproximadamente 84 mil empregos e a geração de mais de 10 mil novos postos de trabalho. O maior segmento atendido pelo programa é o de serviços, com $66,14 \%$ do total dos empréstimos, seguido pelas pequenas atividades comerciais, com $23,33 \%$ dos atendimentos. Já o tempo nas atividades dos clientes é acima de três anos, sendo que apenas $10 \%$ deles têm até um ano na atividade econômica atual.

\section{4-O ESTUDO DE CASO E SEUS PRINCIPAIS RESULTADOS}

\section{1-Procedimentos metodológicos}

O estudo de caso, segundo Gil (2002), descreve um estudo profundo e exaustivo de um determinado objeto, de maneira que seja possível obter um conhecimento mais amplo e detalhado da temática analisada. Para tanto, neste estudo combinou-se a utilização de informações secundárias obtidas junto à instituição com informações coletadas diretamente junto aos clientes e colaboradores da referida instituição previamente selecionados.

Para a aplicação direta de questionários foram selecionados dois grupos distintos de entrevistados: os agentes de crédito da instituição e os clientes da mesma. Para tanto, foram entrevistados 11 agentes locais de crédito e 10 clientes do Banco da Família. A escolha dos agentes de crédito obedeceu ao critério da disponibilidade e voluntariedade para responder o questionário. Já os clientes foram escolhidos nos bairros onde a instituição tem maior inserção. Neste caso, cinco dos entrevistados residiam no bairro Habitação; dois no bairro 
Coral e três no bairro denominado Centro. Registre-se que todos esses bairros estão localizados na cidade de Lages (SC).

Por meio do questionário buscou-se obter informações quanto à percepção desses informantes em relação às mudanças provocadas pelo microcrédito nas condições de vida e de trabalho das pessoas. Além da caracterização geral do respondente, foram elaboradas questões relativas à percepção sobre mudanças no trabalho e no nível de renda, bem como nas melhorias na qualidade de vida das pessoas.

Após a aplicação de todos os questionários, as informações foram organizadas e tabuladas em planilhas do Excel, para posterior construção de gráficos e tabelas que serviram de base para a elaboração de análises qualitativas sobre as distintas percepções dos respectivos entrevistados. Os principais resultados da pesquisa de campo são apresentados na sequência.

\section{2 - A Percepção dos clientes do Banco Família}

Em termos de caracterização dos clientes entrevistados, nota-se que oito eram do sexo feminino, sendo que cinco dessas mulheres situavam-se na faixa etária de 51 anos ou mais de idade. Quase todas eram casadas e com um número elevado de filhos, nunca inferior a três. Com isso, o núcleo familiar em praticamente todos os casos era composto por, no mínimo, cinco pessoas.

Em termos de relação com o sistema bancário tradicional, apenas $50 \%$ dos entrevistados participavam desse sistema, porém a grande maioria tendo conta bancária há pouco tempo. Observa-se que, enquanto a bancarização dos clientes é baixa, o mesmo não acontece com o tempo em que são clientes do Banco da Família, pois 70\% dos entrevistados possuíam mais de cinco anos como clientes, revelando que possuíam um bom vínculo e histórico com a instituição.

No que se refere à profissão e setor de atividade, $40 \%$ dos entrevistados se autodenominaram costureiras; $40 \%$ comerciantes; e $20 \%$ do setor de serviços, sendo uma cabeleireira e uma depiladora. Neste universo, as costureiras foram aquelas que apresentaram características mais diversas, pois todas demonstraram que também prestam serviços e, muitas vezes, também comercializam algumas peças de roupas nos bairros.

Quanto à renda familiar, 80\% declararam possuir uma renda de até R \$2.000,00, sendo que duas entrevistadas possuíam renda familiar acima deste valor. Nenhum entrevistado 
afirmou ter renda familiar abaixo de $\mathrm{R} \$ 1.000,00$, o que pode estar sinalizando que o programa não está totalmente focalizado em clientes de baixa renda.

Indagados sobre os efeitos do microcrédito na composição da renda familiar, todos os entrevistados declararam que o microcrédito contribuiu de forma decisiva para o aumento da referida renda. Na sequência, todos foram unânimes em afirmar que tinham ocorrido melhorias em sua qualidade de vida nos últimos anos e que isto derivava do acesso ao microcrédito e aumento da renda.

Os entrevistados foram chamados a indicar os quesitos mais importantes relativos às melhorias em sua qualidade de vida. Com isso, foi possível identificar as principais percepções dos clientes do Banco da Família sobre as mudanças em suas vidas relacionadas ao papel do microcrédito, bem como alguns aspectos que, segundo eles, contribuíram para o desenvolvimento da localidade em que vivem. Dentre as principais informações prestadas, destacaram-se os quesitos aumento dos investimentos em instalações do negócio; crescimento dos negócios; aumento de clientes na região; aumento da renda; e melhoria na autoestima pessoal. Com isso, foi possível estabelecer a seguinte correlação: o acesso ao crédito permite ampliar os investimentos; esta ampliação atrai mais clientes; e, consequentemente, ocorrem melhorias no negócio e na própria renda do empreendedor, o que leva a uma melhoria na qualidade de vida com repercussões positivas sobre a própria autoestima do microempreendedor.

Esta linha de abordagem está em sintonia com diversos autores que discutiram as mudanças e impactos do microcrédito sobre os negócios e as próprias famílias empreendedoras. Barone (2002) menciona que os impactos são de difícil mensuração, porém reconhecidamente positivos. Melhorias nas condições habitacionais são alguns destes fatores positivos para esse autor. E isto foi possível ser observado em alguns casos onde o estabelecimento comercial está localizado na própria casa, a qual recebeu diversas melhorias em suas instalações.

O mesmo autor também menciona o resgate da autoestima como impacto positivo, bem como inclusão e acessos a patamares superiores na alimentação, saúde e educação:

O impacto social do microcrédito, embora de difícil mensuração, é reconhecidamente positivo, resultando em melhores condições habitacionais, de saúde e alimentar para as famílias usuárias. Além disso, contribui para o resgate da autoestima e a inclusão em patamares de educação e consumo superiores. (BARONE, 2002, p. 11)

Evidências de impactos no desenvolvimento local também podem ser interpretadas se considerarmos o aumento dos clientes na região e a cooperação dentro do bairro. Estas 
melhorias acompanham o raciocínio sobre formação de capital social mencionado por autores como Putnam (2000), Buarque (2000) e Mayer (2003), que destacam a importância do capital social para o desenvolvimento local. Em seu prefácio, Barone (2002) afirma que o microcrédito tem muito mais chances de dar certo em ambientes onde já existe um estoque suficiente de capital social.

Em parte, este aspecto pôde ser observado nas respostas dos entrevistados que pertenciam a um mesmo bairro. Investigando a fundação e trajetória deste bairro, constatou-se que é um local que se constituiu de forma cooperativa e onde o capital social parece estar arraigado na comunidade, pelo próprio histórico de construção das casas, da escola e de outros instrumentos comunitários, todos construídos na forma de mutirões pela comunidade.

Além disso, verificou-se que as respostas também trazem conexões com o tema do empoderamento, assunto que também é destacado por diversos autores. Ter mais acesso à saúde, lazer, educação, consumo, confiança nas entidades da comunidade contribui para o empoderamento, bem como o acesso ao crédito que fortalece relações com os fornecedores.

Em seus estudos Mick (2003) afirma que pareceu ser positiva a correlação entre crédito e empoderamento descrevendo que "crédito atrai crédito":

Crédito atrai crédito: a disponibilidade de dinheiro para pagamento à vista, combinada à pontualidade nos pagamentos a prazo, permite o incremento das relações com fornecedores. Crédito gera crédito: a ausência de pressão sobre os recebimentos, decorrente da disponibilidade de capital de giro, favorece a intensificação das relações com os clientes - o empreendedor pode ampliar o volume de produtos ou serviços, o que tende a aumentar sua clientela, e pode diversificar as formas de receber (vendendo fiado, parcelado ou com cheque pré-datado), tornando-se, ele próprio, um credor. (MICK, 2003, p. 222)

Em grande medida estes aspectos aparecem também quando os entrevistados são chamados a informar a finalidade do microcrédito. Para a grande maioria dos casos sobressaiu o aspecto capital de giro, enquanto em menor número destacou-se o crédito de investimento. Todavia, observou-se que, na prática, há uma sobreposição entre capital de giro e capital para investimento, dada a natureza dos próprios negócios.

\section{3 - A Percepção dos agentes de crédito do Banco Família}

Neste item destaca-se a percepção de agentes de crédito do Banco da Família que trabalham na agência localizada na cidade de Lages. Foram entrevistados individualmente 10 desses agentes de crédito, sendo que a primeira parte da entrevista dizia respeito ao perfil dos agentes; a segunda tratava dos aspectos relativos às atividades desenvolvidas; enquanto a 
terceira buscou a percepção destes agentes sobre os impactos do microcrédito na qualidade de vida dos clientes.

Todos os agentes de crédito entrevistados eram do sexo feminino, com concentração na faixa etária entre 30 e 50 anos de idade. Quanto ao tempo de trabalho exercido como agente de crédito no Banco da Família, a maioria trabalhava entre 3 e 6 anos na empresa.

Quanto à formação profissional dos agentes, exceto um entrevistado que possuía graduação incompleta em logística e outro que possuía segundo grau completo, todos os demais possuíam escolaridade superior completa, predominando a formação nas áreas de administração, economia e contabilidade.

Em termos da carteira de clientes, observou-se que a média situou-se em 390 clientes por agente, sendo que a média de clientes atendidos por mês ficou em 89. Dentre as principais atividades cotidianas dos agentes, destacou-se a cobrança de inadimplentes; prospecção de novos clientes; renovações de microcrédito; visitas de acompanhamento; e outras ocupações chamadas de "fechamentos internos", atividades relativas ao próprio funcionamento da instituição.

Após conhecer minimamente o perfil das agentes e alguns aspectos das atividades executadas, passou-se a discutir os impactos do microcrédito sobre a vida dos clientes, sendo que todos os entrevistados foram unânimes em destacar a importância do sistema de crédito para os clientes.

Todos foram unânimes, também, em destacar o quesito crescimento do negócio como elemento mais importante. Em parte, isso se explica pelas externalidades positivas que são geradas a partir do acesso ao microcrédito. Na sequência foram destacados os quesitos relativos ao faturamento e à manutenção dos negócios.

Com isso, é interessante notar que estes aspectos destacados pelos agentes de crédito estão mais ligados ao funcionamento dos negócios do que propriamente aos aspectos pessoais. $\mathrm{O}$ crescimento do negócio tem ligações muito estreita com a visão de aumento do faturamento, que por sua vez tem ligações com o aumento de renda recebida e outras vezes com o aumento do número de empregos, ou até mesmo com ambos. O mesmo pode ser analisado quanto à manutenção do negócio que guarda relações diretas com as demais características, como por exemplo, ampliação do número de clientes e aumento do faturamento final dos negócios.

Um dos fatores de mudança na qualidade de vida dos clientes mais destacados também pelos agentes de crédito foi a eliminação do nome desses clientes dos órgãos de restrições ao 
crédito. Além disso, destacou-se o aumento de consumo em geral; o empoderamento e cooperação comunitária; o acesso ao lazer, à saúde e à educação.

A partir dos quesitos destacados pelas entrevistas junto aos agentes de crédito é possível deduzir que suas respostas e compreensões sobre o sistema estão mais vinculadas a fatores diretamente ligados ao negócio como indutores dos demais aspectos. Ou seja, o crescimento do negócio é o fator determinante, segundo os agentes de crédito, para que outros aspectos mais gerais relacionados à qualidade de vida dos clientes ganhem destaque. Isso se explica porque aproximadamente $80 \%$ dos entrevistados destacaram o crescimento do negócio, dentre todas as alternativas, como principal desencadeador do processo de mudanças. Registre-se que apenas um entrevistado vinculou o tema do crescimento do negócio à formação de capital social.

\section{5 - CONSIDERAÇÕES FINAIS}

Este trabalho analisou a importância do microcrédito para a melhoria da qualidade de vida dos clientes bancários, bem como os possíveis efeitos diretos e indiretos no ambiente local. Para tanto, estudou-se o caso do Banco da Família no município de Lages (SC), considerada uma das experiências mais exitosas nesta área no estado de Santa Catarina.

Com base na literatura especializada observou-se que o microcrédito é uma ferramenta importante para apoiar o desenvolvimento local. No entanto, este instrumento deve ser utilizado em conjunto com outros mecanismos comunitários e sociais para que possa desenvolver todas as potencialidades de uma determinada comunidade, local e/ou região.

O microcrédito é um importante instrumento no processo de resgate de parcelas da população que vivem na informalidade e que são excluídas do mercado tradicional. E a utilização conjunta do microcrédito com laços comunitários fortes, capital social, moedas locais e outros laços de sociabilidade pode significar uma verdadeira mudança econômica e social, no sentido de se desenvolver vocações locais e de se gerar um círculo positivo entre consumo e produção.

Vimos que no estado de Santa Catarina estão em curso algumas das principais experiências de microcrédito no país, com destaque para as características que diferenciam o crédito tradicional do microcrédito produtivo orientado para pequenos negócios e para populações afastadas do sistema bancário tradicional. 
No estado catarinense o assunto microcrédito se expandiu a partir da transformação do Banco de Desenvolvimento do Estado de Santa Catarina (BADESC) em uma agência de fomento do desenvolvimento, sendo que o programa Crédito de Confiança foi a primeira experiência oficial adotada no final dos anos de 1990. Inicialmente, o programa contou com a participação de 10 organizações não governamentais, número que mais tarde passou para 19. Em parte, essa expansão decorreu das mudanças jurídicas com a introdução da legislação específica de OSCIPs. Em 2006 foi constituída a AMCRED-SC com o objetivo de consolidar o trabalho sobre microcrédito em rede em todo o estado de Santa Catarina.

Nesta curta trajetória destacam-se as experiências do Banco do Empreendedor, que é a maior instituição atuante na região da Grande Florianópolis; a Instituição Comunitária de Crédito Blumenau Solidariedade - BLUSOL - que atua na região do vale do Itajaí; e o Banco da Família, com atuação na região do Planalto Serrano e que foi objeto de estudo de caso específico.

O Banco da Família é atualmente uma das maiores instituições no programa microcrédito de SC, tanto em termos de valores emprestados como de carteira de clientes, inclusive com algumas ações em estados vizinhos. Por meio de pesquisa de campo junto aos clientes e agentes de crédito foi possível observar a contribuição do microcrédito, tanto em termos das melhorias provocadas na qualidade de vida dos clientes como nos possíveis efeitos sobre o desenvolvimento local.

Nos resultados da pesquisa percebeu-se uma característica deste público que também já fora constatada por outros autores e pela literatura específica: a baixa bancarização. No caso do Banco da Família, somente $20 \%$ de seus clientes entrevistados possuíam conta em banco a mais de cinco anos, ao mesmo tempo em que aproximadamente $70 \%$ dos clientes entrevistados do BF tinham uma relação com esta instituição de mais de cinco anos. Isto demonstra a importância da instituição nas relações financeiras locais, especialmente quando se considera que a grande maioria dos entrevistados possuía idade igual ou superior a 40 anos.

Um dos impactos bastante ressaltados pelos entrevistados durante os trabalhos de campo diz respeito aos efeitos do microcrédito sobre a renda das famílias. Mesmo que a amostra tenha evidenciado que o programa do Banco Família não esteja focalizado em pessoas com renda familiar abaixo de $\mathrm{R} \$ 1.500,00$, notou-se que todos os entrevistados apontaram como uma das grandes influências do microcrédito a melhoria dos negócios, fato que, consequentemente, produz efeitos positivos sobre a renda familiar. 
Além disso, outra consideração bastante destacada pelos entrevistados sobre melhorias na qualidade de vida dos clientes foi o fato de que com investimentos nas instalações dos negócios, geram-se efeitos correlatos, como é o caso do aumento do nível de renda e a melhoria da autoestima dos próprios empreendedores.

Foi destacado, ainda, que o microcrédito provoca alguns impactos no ambiente local. Isto ficou evidenciado a partir da ocorrência de aumento dos clientes e fornecedores na região; do melhoramento da cooperação dentro do bairro; e do aumento das relações de confiança entre os moradores de um bairro, cidade e até mesmo região.

Paralelamente a isto, apareceram nas entrevistas elementos mais ligados à questão do capital social e da cooperação entre os agentes locais, uma vez que o grau de confiança nas entidades públicas locais e nas próprias entidades da comunidade tendeu a aumentar. Com isso, o acesso ao crédito possibilitou, inclusive, que alguns clientes tivessem também acesso a serviços de lazer que anteriormente não possuíam.

De uma maneira geral, o estudo revelou que o microcrédito é um importante instrumento retroalimentador do desenvolvimento local, mesmo que em pequenas dimensões do ponto de vista de pessoas contempladas, pois comprovadamente contribui para melhorar as condições de vida das mesmas. Esta afirmativa ficou evidente tanto nas entrevistas com os clientes como nos questionários respondidos pelos agentes de crédito do programa.

Em função dos limites amostrais deste estudo, sugere-se que trabalhos futuros ampliem as interlocuções juntos aos clientes para poder captar com maior clareza o papel que vem sendo desempenhado pelo microcrédito nas regiões e no próprio estado de Santa Catarina. Para tanto, a realização de estudos em outras instituições visando contemplar análises comparativas a partir de alguns parâmetros comuns seria importante. Por fim, estudos mais gerais que procurassem tratar a questão do microcrédito no âmbito do desenvolvimento local também seriam relevantes, pois poderiam trazer valiosas contribuições para diversas áreas de conhecimento não restritas apenas aos aspectos financeiros.

\section{REFERÊNCIAS BIBLIOGRÁFICAS}

ALVES, Pedro Ananias. Vozes da Solidariedade. In: SACHET, Celestino; WATERKEMPER, Margaret; SACHET, Sérgio. A Vitória do Crédito de Confiança. Florianópolis: BADESC, 2001, p. 57-63.

ALVIM, Valdir. Assistência Financeira do Grupo Banco Mundial ao Brasil: ajustamento do setor financeiro e programas de privatização - o PROES e o caso particular do SFBESC. Tese 
de doutorado em Sociologia Política. UFSC, 2007. Disponível em: http://repositorio.ufsc.br/xmlui/bitstream/handle.

ARAÚJO, Alexandre Guerra de et al. SISTEMA FINANCEIRO E AS MICRO E PEQUENAS EMPRESAS: Diagnósticos e Perspectivas. Carlos Alberto dos Santos (org). 2. ed. Brasília: SEBRAE, 2004. Disponível em:

$<$ http://www.biblioteca.sebrae.com.br/bds/bds.nsf/86EA8851BFB82DBA03256EEB006CC2 09/\$File/NT0008D7F2.pdf $>$. Acesso em: 10 jun. 2012.

BADESC. Site corporativo. Disponível em: <http://www.badesc.gov.br/>. Acesso em: 10 nov. 2012.

Banco Central do Brasil. Livro de microfinanças. Disponível em: <http://www.bcb.gov.br/>.

Banco da Família. Site Corporativo. Disponível em: <http://www.bancodafamilia.org.br/>. Acesso em: 30 nov. de 2012.

Relatório Financeiro 2011, MicroRate, disponível em:

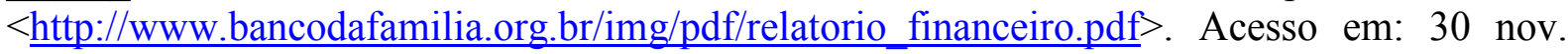
2012.

Banco do Empreendedor. Site Corporativo. Disponível em: $<\mathrm{http}: / /$ www.bancodoempreendedor.com.br/>. Acesso em: 30 nov. 2012.

Banco Nacional de Desenvolvimento Econômico e Social - BNDES. Programa de Microcrédito. Disponível em: $<\underline{\text { http://www.bndes.gov.br/SiteBNDES/bndes/bndes_pt/Institucional/Apoio_Financeiro/Progr }}$ amas_e_Fundos/Microcredito/microcredito_condicoes.html $>$. Acesso em maio 2012.

Banco Palmas. Site Corporativo. Disponível em: $<$ http://www.bancopalmas.org.br $/>$. Acesso em 30 de novembro de 2012.

BARONE, M. Introdução ao microcrédito. Brasília: Conselho da Comunidade Solidária, 2002.

BLUSOL. Site Corporativo. Disponível em: $<$ http://www.blusol.org.br/>. Acesso em: 24 nov. 2012.

BUARQUE, S. C. Construindo o desenvolvimento local sustentável. 4. ed. Rio de Janeiro: Garamond, 2008.

GIL, Antônio Carlos. Métodos e técnicas de pesquisa social. 6. ed. São Paulo: Atlas, 2002.

LIMA, Shanna Nogueira. Microcrédito como política de geração de emprego e renda. Revista do Bndes 32, p.64-72, dez. 2009.

MARTINS, R.A., Vaz, J. C., LIMA CALDAS, E. A gestão do desenvolvimento local no Brasil: (des)articulações de atores, instituições e territórios. Revista de Administração Pública (RAP), v.44, n.3, p.559-590, mai/jun.2010. 
MICK, Jacques. O caráter social do microcrédito. Blumenau (SC): Mimeo (Anais do Seminário Latino-Americano de Microcrédito), 2003.

MOREIRA, L. M. F.; ABRAMOVAY, R. Laços sociais no monitoramento do microcrédito. Pesquisa \& Debate (Online), v. 18, p. 113-129, 2007. Disponível em: $<$ http://www.pucsp.br/pos/ecopol/downloads/edicoes/(31)luis mauricio.pdf $>$ Acesso em: 20 nov. 2012. PORTOSOL. Site Corporativo. Disponível em: <http://www.portosol.com/>. Acesso em: 12 nov. 2012.

NOGUEIRA DA COSTA, F. Microcrédito no Brasil. In: Matos, F.; Macambira, J.; Cacciamali, M. C. A atividade e a política de microcrédito no Brasil: visões sobre sua evolução e futuros desafios. Fortaleza (CE): IDT-USP, 2014.

PUTNAM, Robert D. Comunidade e democracia. A experiência da Itália moderna. Rio de Janeiro: Editora FGV, 2000 (original: Making democracy work. Civic traditions in modern Italy. Princeton, NJ: Princeton University Press, 1993).

SANTOS, A. GOIS, F. F. Microcrédito e desenvolvimento regional/Fundação Paulo Bonavides. Instituto para o desenvolvimento de estudos econômicos, sociais e políticas públicas. Fortaleza: Premius, 2011. 384p.

SÃO PAULO. Governo do Estado de São Paulo. Banco do Povo chega a R\$ 1 Bilhão em empréstimos. Notícia em 20/08/2012. Disponível em: $<$ http://www.saopaulo.sp.gov.br/spnoticias/lenoticia.php?id=221719>. Acesso em: $06 \mathrm{dez}$. 2012.

SCHREIBER, José Gentil. O Papel do Microcrédito no Combate à Pobreza: Avaliação do impacto do Microcrédito sobre a renda dos microempreendedores, clientes do Banco do Empreendedor. Tese de doutorado em Desenvolvimento Econômico, UFPR, Curitiba, 2009.

TOSCANO, Idalvo. MICROCRÉDITO: Da Iniciativa Local ao Centralismo Estatal. fev. 2002.

VASCONCELOS, Daniel de Santana. Microcrédito, combate à pobreza e desenvolvimento econômico: Uma análise do debate sobre a focalização e sustentabilidade dos programas de microfinanças; Prêmio Ipea 40 anos. Ipea, 2006.

YUNUS, M. O Banqueiro dos Pobres. São Paulo: Ática, 2000. 